\title{
The Impact of GNMA Futures Trading On Cash Market Volatility
}

\author{
John B. Corgel* and Gerald D. Gay**
}

\section{INTRODUCTION}

A general conclusion that can be drawn from theoretical analyses of spot market volatility when futures markets exist is best summarized by Turnovsky [1983, p. 1364] who states "under their (theoretical studies) respective assumptions, the futures market almost certainly stabilizes the spot price."' This suggests that trading in futures contracts may originate when cash markets experience considerable volatility. Indeed, futures trading on a variety of financial instruments was initiated shortly after periods of historically high interest rates.

Nevertheless, speculators in futures markets are frequently blamed for promoting cash market volatility, such that, the introduction of futures trading in a financial instrument like Government National Mortgage Association pass-through securities (GNMAs) may serve to increase rather than decrease volatility in the cash market. Although not supported by theoretical analyses, if this "speculator" theory is correct, then investors in mortgage backed securities would find GNMAs less attractive because of greater volatility in prices following futures trading, and the introduction of futures trading in GNMAs may be viewed as being adverse to ongoing public policy and programs.

As an empirical question, the issue of whether trading in GNMA futures has increased or decreased volatility in the cash market is as yet unresolved. The existing empirical literature, reviewed in the next section, is both flawed and contradictive. Results from some studies indicate that the introduction

\footnotetext{
*Department of Real Estate and Urban Affairs, Georgia State University, Atlanta, Georgia 30303.

**Department of Finance, Georgia State University, Atlanta, Georgia 30303.

Date Received: September 7, 1983; Revised: February 15, 1984.
} 
of futures trading decreases volatility in the GNMA cash market while in one noted study an increase in volatility is discovered. Each of the previous studies, however, fails on at least one of the following accounts: 1) improper measurement of cash market volatility; 2) a lack of emphasis on the impact of the appropriate event - the introduction of futures trading in GNMAs; and 3) an absence of concern for holding constant other factors that may contribute to cash market volatility.

The purpose of this study is to empirically investigate the effect of the introduction of futures trading in GNMAs on volatility in the GNMA cash market. Through the use of intervention analysis (see Box and Tiao 1975) special consideration is given to the impact of the event, including any potential leading or lagging effects. Also, the model used in this analysis incorporates other factors that may affect cash market volatility. This study, therefore, represents a critical reexamination of the empirical issues. The remainder of the article is comprised as follows. The second section contains a review of the literature regarding cash market effects from futures market activity. In the third section, a model of GNMA cash market volatility is presented along with descriptions of the data and procedures used in estimating model parameters. Section four presents the results of empirical tests for the effects of the introduction of futures market trading in GNMAs. Conclusions and a discussion of some implications of the results are provided in the final section.

\section{PREVIOUS RESEARCH}

An in-depth review of the literature on the cash market effects of future trading has been provided recently in a dissertation by Cohen [1982]. Following Cohen, the literature can be divided into three categories along commodity lines. These are: 1) storables, such as gold and certain agricultural commodities like onions; 2) nonstorables, such as pork bellies; and 3) financial instruments, such as T-bonds.

\section{Storable Commodities}

Virtually all of the research on the effects of future trading in storable commodities is in reaction to a government ban on onion futures trading in 1958. The leading work on this issue is by Working [1960] who concludes, in contrast to Congressional findings, that futures tradings in onions was not responsible for the wide variations in onion cash prices that had been experienced prior to the ban on futures trading. The study period 1930-1958 is subdivided into three subperiods: 1930-1941, when no futures trading occurred; 1946-1949; when little hedging was occurring; and 1949-1958, a 
period of significant hedging (presumed to be a period of significant speculation). The data indicate that cash price volatility was lowest in the third subperiod. Subsequent research by Gray [1963] and Johnson [1973] resulted in similar conclusions.

\section{Nonstorable Commodities}

Powers [1970] argues that the results from studies of storable commodities are not generalizable to continually produced nonstorables. He separates the variation in certain nonstorable commodity prices into systematic (resulting from changes in supply and demand) and random components (noise). A reduction in the random component is seen as socially beneficial. For each commodity studied, Powers finds smaller estimated variances in the random component during periods of futures trading. Similarly, Taylor and Leuthold [1974] find no significant difference in the total variance of cash prices of cattle between periods of futures trading and no futures trading using annual data, but smaller variances in periods of futures trading with monthly data.

Finally, Cox [1976], using a model based upon the efficient market hypothesis, investigates the autoregressive structure of cash prices for commodities in periods with and without futures trading. Like virtually all previous studies, Cox concludes that futures trading has not had a destabilizing effect upon the structure of cash prices in commodities, but provides "more accurate signals for resource allocation" than when no futures trading was occurring (p. 1235).

\section{Financial Instruments}

Since the introduction of trading in interest rate futures in October 1975, beginning with the GNMA contract, several studies investigate how the creation of these markets has affected prices in related cash markets. Studies by Gardner [1980] and Cohen [1982] focus upon the effects of T-Bill futures trading. Both studies involve a comparative analysis of cash price volatility in subperiods before and after the beginning of futures trading. Also, both conclude that the cash price volatility is not significantly higher with futures trading. but may actually be lower.

Froewiss [1978], in the first study of its kind for GNMA markets, uses the same before and after futures trading subperiod approach and reaches the same conclusions as did researchers working in storables, nonstorables, and the other financial futures cited previously. Cohen [1982, pp. 69-71], however, reveals some serious econometric flaws in the Froewiss study that also apply to Gardner's methodology. 
Figlewski's [1981] study of the price effects of the GNMA futures market relies upon a standard deviation measure of cash price volatility for GNMA $8 \%$ and $9 \%$ coupons computed monthly from January/February 1975 to February 1979. Two different coupon instruments were used due to technical factors in the futures market resulting in sometimes one and sometimes the other security being the delivery instrument. Four types of factors are used to explain his carefully constructed volatility series: 1) volatility in related markets, measured as the volatility in ten-year government bonds and ten-year federal agency bonds; 2) breadth and liquidity of the GNMA cash market, measured as the volume of new issues of GNMAs for the current month plus the volume of the secondary market and the volume of new series for the future four months; 3) the level of GNMA prices: and 4) futures market variables, such as average open interest for the month, total trading volume for the month, and price volatility of some GNMA futures contracts.

Figlewski ran OLS regressions using the volatility of the GNMA 8's and 9's as dependent variables. The volatility of government bonds was not found to be useful in explaining GNMA volatility, while the variables measuring the size of the GNMA market generally had significant negative coefficients. Also, average GNMA spot prices were found to be positively related to the volatility of the GNMA 8's, but were not a significant variable in the GNMA 9's equation. Finally, the variables of interest were the futures market measures. Open interest was significantly positive for the 8's and the volume of futures trading was significantly positive for the 9's. Futures price volatility, therefore, was positively related to spot price volatility.

Figlewski interprets this set of results as indicating that GNMA futures trading caused increased volatility in the GNMA cash market. Regressions such as these, however, do not necessarily lead to conclusions with respect to causation, and in this case theoretical arguments would suggest that the increased volatility of cash prices caused the observed increase in trading activity (see Seiders 1981).

Overall, Figlewski's statistical analysis does not appear sensitive enough to tell us much about the price effects of futures trading in GNMAs and his casuality arguments do little to justify his conclusion that futures trading increased the volatility of cash prices. The real issue is the volatility effect of the introduction of futures trading vis-a-vis no-futures trading, and on this question Figlewski's results shed little light. Moreover, Figlewski attributes the increased volatility in the cash market to the "relative inexperience of some futures traders with GNMA securities" (p. 456). This hypothesis is not tested directly and one would expect that its effects, if they exist, would diminish over time.

Recently, Simpson and Ireland [1982] completed a study of the impact of futures trading on the price volatility of GNMA securities using a time-series 
intervention approach. The findings indicate that the introduction of futures trading in GNMAs had no substantial effect on GNMA cash price volatility. Unfortunately, Simpson and I reland used the first difference in GNMA cash market yields as a dependent variable instead of Figlewski's more advanced volatility measure. Also, they failed to hold constant the effects of the seasoning of the GNMA cash market over the study period. These shortcomings represent serious flaws in their empirical analysis.

\section{METHODOLOGY}

This investigation of how the introduction of futures trading in GNMAs has affected the GNMA cash market begins with a model of cash market volatility. The following are considered important explanatory variables: volatility in related debt markets, breadth and liquidity of the GNMA cash market, the level of GNMA prices, and the introduction of futures trading in GNMAs.

Accounting for volatility in related debt markets controls for the volatility of interest rates in general (Froewiss 1978 and Figlewski 1981). Volatility in the GNMA cash market should also be affected by factors associated with market liquidity. One may expect volatility to decrease as the volume of secondary market trading and the volume of new securities supplied to the market increases. In addition, volatility in the cash market may be influenced by the level of cash market prices. The direction of change, however, is uncertain. If yields embody inflationary expectations and the variability of inflation increases with higher levels of inflation, then lower prices should be associated with increased volatility. Yet, GNMA dealers should be more willing to trade in securities when prices are lower, thus serving to stabilize the cash market. Finally, the null hypothesis is tested that the introduction of futures trading in October 1975 had no significant effect upon volatility in the GNMA cash market.

\section{Data Description}

To proxy GNMA cash market volatility, the standard deviation of the day-to-day yield $(\mathrm{y})$ changes during a given month $\mathrm{t}$ for each coupon issue outstanding is first calculated according to:

$$
v_{1}=\left[\frac{\sum_{i=1}^{N_{1}}}{} \frac{\left(y_{i}-y_{i-1}\right)^{2}}{N_{t}}\right]^{1 / 2}
$$


where $\mathrm{N}_{1}$ is the number of observations for a particular issue during a given month. ${ }^{2}$ This measure was selected as it avoids problems associated with using variances around a long-term mean when the data contain a trend (Figlewski 1981). Using Wall Street Journal data, $V_{1}$ was computed for each GNMA issue outstanding during each month over the period August 1974 through September 1979. A list of each issue along with the period it traded during our sample period is presented in Table 1. The beginning point for the study was dictated by data availability while the end point was selected to avoid problems associated with significant changes in Federal Reserve policy during October 1979. Following the calculation of the monthly yield volatility for each issue, an average monthly volatility series, $\overline{\mathrm{V}}_{\mathrm{t}}$, was constructed for the GNMA market. The series consisted of sixty-two monthly observations.

Volatility in related debt markets is approximated with a volatility index on Treasury Bonds. This index was constructed from Wall Street Journal data collected on the three bonds having maturities closest to twelve years. Twelve years was selected as this is typically assumed as being the effective maturity of GNMA securities due to prepayment. Next, the daily yields of the three bonds were averaged and a volatility index, $\mathrm{TB}_{\mathrm{t}}$, was calculated according to equation (1).

The breadth and liquidity of the GNMA cash market was measured in two ways: the monthly dollar volume of GNMA secondary market transfers, $S M T_{t}$, and the monthly dollar volume of new GNMA issues, NGI. Data for these measures were obtained from GNMA.

\section{Statistical Analysis}

In order to analyze the impact of GNMA futures trading on GNMA cash market volatility, an interrupted time-series technique known as intervention analysis is used. Intervention analysis has been used to model the impact of many economic events, for example, the impact of air pollution control laws (Box and Tiao 1975) and the impact of gun control laws (Zimring 1975), Moreover, intervention analysis allows direct focus on the dynamic characteristics of the response to the intervention, such as the speed of adjustment, as well as the degree and nature of any over- or underreaction.

Following Box and Tiao [1975] the time series of GNMA volatility $\left(\overline{\mathrm{V}}_{\mathrm{t}}\right)$ is modeled as:

$$
\bar{V}_{t}=W_{t}+I_{t}+N_{t}
$$

where $\bar{V}_{t}=$ average GNMA yield volatility in month $t$; 
TABLE I

GNMA Issues Used in Analysis

$\begin{array}{lr}\text { Coupon (\%) } & \text { Dates Spanned in S } \\ 6.5 & 8 / 74-4 ; 79 \\ 8 & 8 / 74-9 ; 79 \\ 8.5 & 8 / 74-9 ; 79 \\ 9 & 2 ; 75-9 ; 79 \\ 7.25 & 11 ; 76-2 ; 78 \\ 7.5 & 1 / 77-9 ; 79 \\ 8.25 & 4 / 78-9 ; 79 \\ 9.50 & 6 / 79-9 ; 79\end{array}$

$\mathrm{W}_{\mathrm{t}}$ = the component of $\vec{V}_{t}$ which can be explained by a set of exogenous variables, $X_{t}(s)$, such as the volatility in related debt markets in addition to the breadth and liquidity of the GNMA cash market;

$I_{t}=$ the component of the residual attributable to the intervention of GNMA futures trading; and

$\mathrm{N}_{\mathrm{t}}=$ noise component which cannot be explained in terms of other exogenous variables or the intervention variable.

The noise component of the model, $\mathrm{N}_{\mathrm{t}}$, can be modeled as an orthodox univariate ARIMA process (Box and Jenkins, 1976) as follows:

$\mathrm{N}_{\mathrm{t}}=\frac{\theta(\mathrm{B})}{(1-\mathrm{B})^{\mathrm{d}} \phi(\mathrm{B})} \mathrm{a}_{\mathrm{t}}$

where $a_{t}$ is a sequence of independently distributed random variables $\sim \mathrm{N}\left(0, \sigma^{2}\right), \theta(\mathrm{B})$ is a moving average operator of order $\mathrm{q}, \phi(\mathrm{B})$ is an autoregressive operator of order $p, d$ is the degree of differencing necessary to achieve stationarity, and $B$ is the backshift operator such that $B R_{t}=R_{t-1}$.

In the case of one exogenous variable the relationship between $W_{t}$ and $X_{t}$ is modeled as follows:

$$
W_{t}=\frac{\left(W_{0}-W_{1} B-\ldots-W_{S} B^{S}\right)}{\left(1-\delta_{1} B-\ldots-\delta_{r} B^{r}\right)} X_{t-b}
$$


$W_{t}=\frac{W(B)}{\delta(B)} \quad X_{t-b}=v(B) X_{t-b}$

where $\mathrm{b}=$ delay or time lag parameter,

W (B) moving average operator,

$\mathrm{S}(\mathrm{B})=$ autoregressive operator, and

$v(B)=\frac{W(B)}{\delta(B)}=\begin{aligned} & \text { transfer function that transfers values of } X \\ & \text { (input) to } W \text { (output). }\end{aligned}$

Additional transfer functions of similar form can be added to account for the effects of other exogenous variables.

In an analogous manner, the effect of the intervention on $\bar{V}_{1}$ is modeled as:

$\mathrm{I}_{1}=\frac{\mathrm{W}^{\prime}(\mathrm{B})}{\delta^{\prime}(\mathrm{B})} \quad \xi_{\mathrm{t}-\mathrm{b}}=\mathrm{v}^{\prime}(\mathrm{B}) \xi_{\mathrm{t}-\mathrm{b}}$

where $\xi_{t}$ constitutes the intervention variable. In view of the permanency of the GNMA futures trading, the intervention variable, $\xi_{t}$, will be represented as a step function of the following form:

$\xi_{1}=\left[\begin{array}{l}0: \text { prior to GNMA futures trading } \\ 1: \text { thereafter. }\end{array}\right.$

Substituting equations (3), (4), and (5) into (2) results in the following:

$\mathrm{V}_{\mathrm{t}}=\mathrm{v}(\mathrm{B}) \mathrm{X}_{\mathrm{t}-\mathrm{b}}+\frac{\mathrm{W}^{\prime}(\mathrm{B})}{\delta^{\prime}(\mathrm{B})} \xi_{\mathrm{t}-\mathrm{b}}+\frac{\theta(\mathrm{B})}{(1-\mathrm{B})^{\mathrm{d}} \phi(\mathrm{B})} \mathrm{a}_{\mathrm{t}}$

The next section provides estimates of the parameters of the transfer function and the noise model using standard Box-Jenkins techniques while the structure of the intervention component is examined using several alternative forms that must be specified a priori.

\section{RESULTS}

As mentioned previously, three exogenous variables were hypothesized as possibly influencing GNMA cash market volatility $\left(\bar{V}_{t}\right)$ : volatility in related debt markets $\left(\mathrm{TB}_{\mathrm{t}}\right)$, GNMA secondary market transfers $\left(\mathrm{SMT}_{\mathrm{t}}\right)$, and new 
GNMA issues ( $\left.\mathrm{NGI}_{\mathrm{t}}\right)$. The first step in the analysis is to examine the crosscorrelation function at various lags between $\bar{V}_{t}$ and each of the exogenous variables. These results are presented in Table 2. Inspection of the crosscorrelation function between (1) $\overline{\mathrm{V}}_{t}$ and $S M T_{t}$, and (2) $\overline{\mathrm{V}}_{t}$ and $N G I_{t}$ indicates no significant relationship at any of the lags. However, inspection of the cross-correlation function between $\bar{V}_{1}$ and $T_{B}$, indicates a significant relationship at lags zero and one. This information is later used in specifying the appropriate transfer function.

Several types of long-term responses to the introduction (intervention) of GNMA futures trading on volatility were modeled and tested including:

(a) a single abrupt shift indicating a permanent change in volatility. This change in volatility may be either positive or negative, (see the first section of this study): $I_{1}=W_{0} \xi_{1}$;

(b) a shift followed by another shift of permanent duration indicating a lagged effect or an abrupt seasoning of the market: $I_{t}=\left(W_{0}-W_{1} B\right) \xi_{t}$;

(c) a gradual change resulting in an eventual permanent shift indicating a gradual seasoning of the market: $I_{1}=\frac{W_{o}}{(1-\delta B)} \xi_{t}$.

Figure 1 provides a graphic representation of these responses.

The transfer function and intervention model specified in equation (6) was estimated using unconditional least squares (also known as the backcasting method) for each of the three responses described above. Estimates of the parameters for each of the models are presented in Table 3 as well as the summary statistics. The Box-Pierce $Q$ statistics (distributed chi-square) were all insignificant at the .01 level suggesting that the error was successfully reduced to white noise in all cases. Furthermore, a visual inspection of the autocorrelation functions confirmed this result.

Examination of the three models presented in Table 3 reveals that only model (a) conforms to the hypothesized response as indicated by the significant coefficient on the intervention variable. Since the coefficient is negative, we interpret this finding as an indication that the GNMA cash market experienced a permanent reduction in the level of volatility immediately following the introduction of GNMA futures trading.

The above results indicate that the GNMA cash market as a whole experienced a significant decline in volatility. To examine whether the model's specification extends similarly to individual coupon series, the tests were repeated for the GNMA $8 \%$ coupon series (V8). This series was selected since 1) data for this series were available throughout the entire 
Figure 1

Long-Term Volatility Responses

to the Impact of GNMA Futures Trading

INPUT ${ }^{\xi_{t}}$

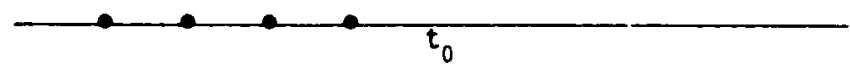

OUTPUT $\frac{W^{\prime}(B)}{\delta^{\prime}(B)}$
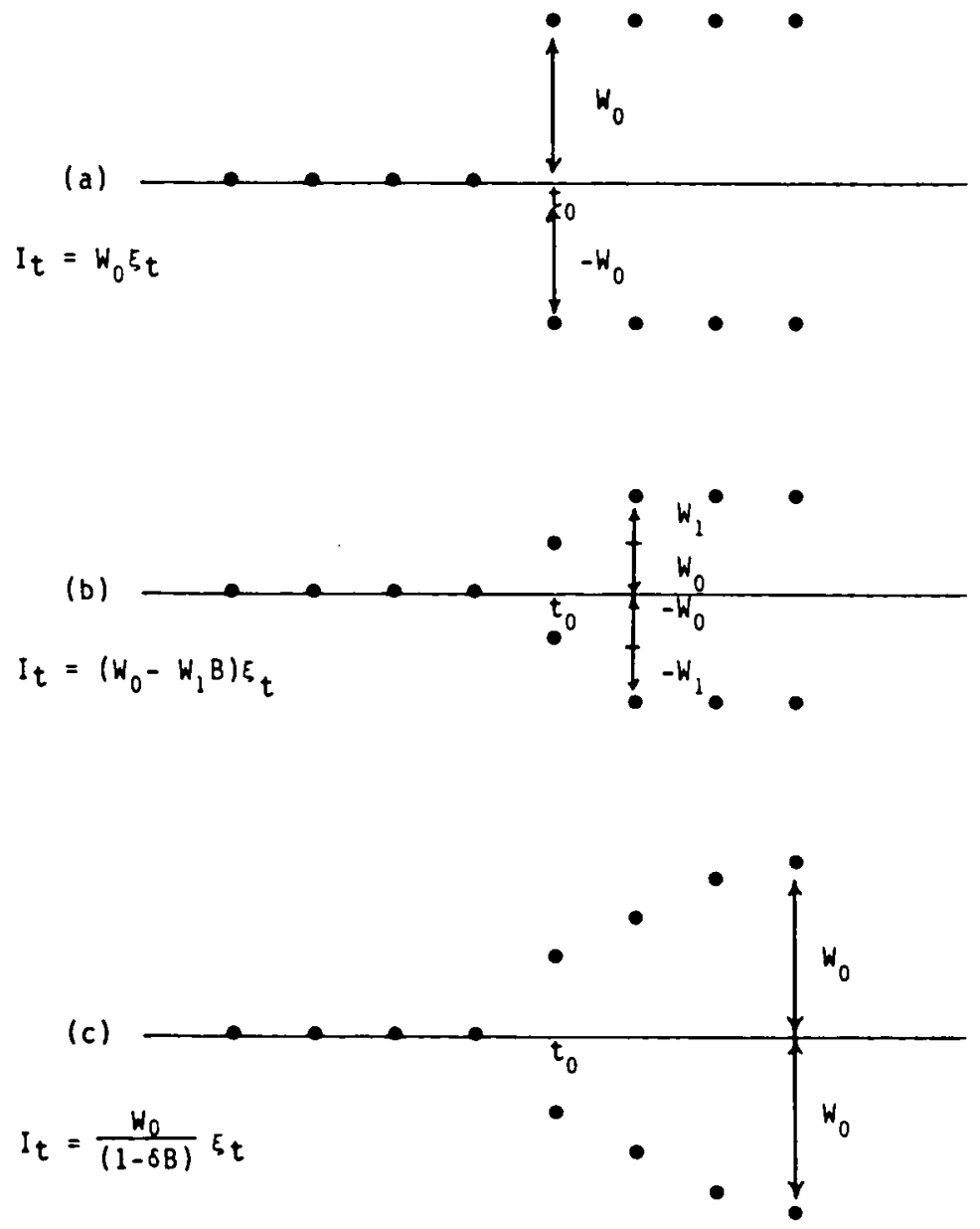
TABLE 2

Cross-Correlations Between GNMA Volatility and Selected Exogenous Variables ${ }^{\mathrm{a}}$ (Correlation between $\bar{V}_{t}$ and $X_{t}+j$ for $j=-4$ to +4 )

(a) GNMA Volatility $\left(\bar{\nabla}_{t}\right)$ and Related Debt Market Volatility $\left(\mathrm{TB}_{t}+\mathrm{j}\right)$

\begin{tabular}{ccccccccc}
\hline$\rho_{-4}$ & $\rho_{-3}$ & $\rho_{-2}$ & $\rho_{-1}$ & $\rho_{0}$ & $\rho_{1}$ & $\rho_{2}$ & $\rho_{3}$ & $\rho_{4}$ \\
\hline .05 & .04 & .12 & -.06 & $.45^{\mathrm{b}}$ & $.24^{\mathrm{b}}$ & -.09 & -.11 & -.09 \\
$(.13)$ & $(.13)$ & $(.13)$ & $(.13)$ & $(.13)$ & $(.13)$ & $(.13)$ & $(.13)$ & $(.13)$ \\
\hline
\end{tabular}

(b) GNMA Volatility $\left(\bar{\nabla}_{t}\right)$ and Secondary Market Transfers $\left(\mathrm{SMT}_{\mathrm{t}+\mathrm{j}}\right)$

\begin{tabular}{ccccccccc}
\hline$\rho_{-4}$ & $\rho_{-3}$ & $\rho_{-2}$ & $\rho_{-1}$ & $\rho_{0}$ & $\rho_{1}$ & $\rho_{2}$ & $\rho_{3}$ & $\rho_{4}$ \\
\hline .03 & .09 & .09 & -.06 & .03 & .12 & .05 & .06 & .10 \\
$(.13)$ & $(.13)$ & $(.13)$ & $(.13)$ & $(.13)$ & $(.13)$ & $(.13)$ & $(.13)$ & $(.13)$ \\
\hline
\end{tabular}

(c) GNMA Volatility $\left(\bar{V}_{t}\right)$ and New GNMA Issues $\left(\mathrm{NGI}_{t}+\mathrm{j}\right)$

\begin{tabular}{ccccccccc}
\hline$\rho_{-4}$ & $\rho_{-3}$ & $\rho_{-2}$ & $\rho_{-1}$ & $\rho_{0}$ & $\rho_{1}$ & $\rho_{2}$ & $\rho_{3}$ & $\rho_{4}$ \\
\hline .04 & .09 & .07 & -.11 & .07 & .05 & .11 & .13 & .01 \\
$(.13)$ & $(.13)$ & $(.13)$ & $(.13)$ & $(.13)$ & $(.13)$ & $(.13)$ & $(.13)$ & $(.13)$ \\
\hline
\end{tabular}

${ }^{a}$ Standard errors are in parentheses.

${ }^{\mathrm{b}}$ Significant at $\alpha=.05$ significance level

study period, and 2) this coupon was sometimes the "cheapest-to-deliver" during this period. ${ }^{3}$ Results for the GNMA $8 \%$ coupon series are presented in Table 4. (The cross-correlation functions are similar to those reported in Table 2 and thus are not reported.) These results for the GNMA 8\% coupon series are consistent with the results found for the overall series.

\section{CONCLUSIONS AND POLICY IMPLICATIONS}

Previous empirical research on the effects of the introduction of GNMA futures trading on GNMA cash market volatility has resulted in three divergent conclusions. First, Froewiss [1978] concludes that futures trading 


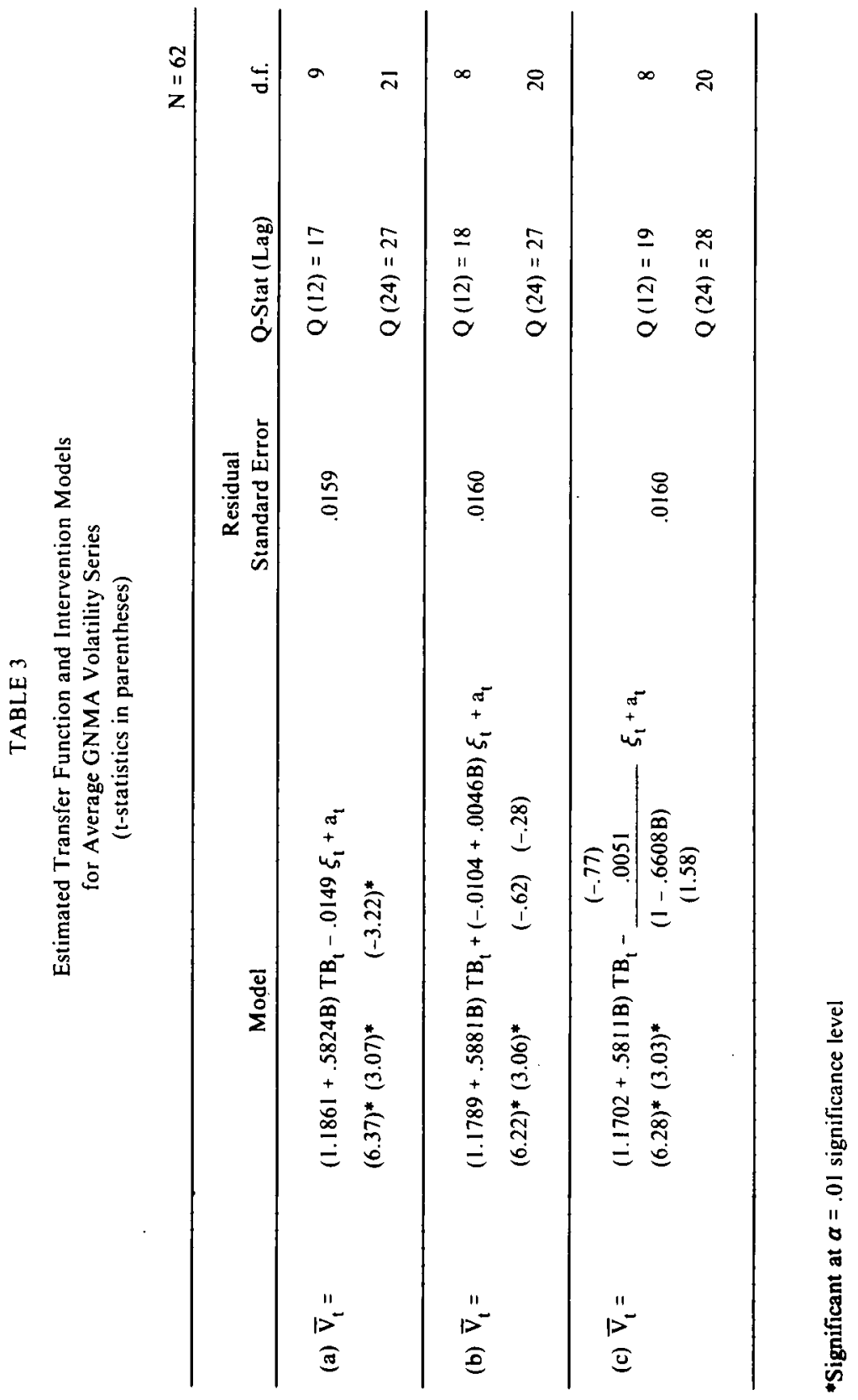


TABLE 4

Transfer Function and Estimated Intervention Models for GNMA 8\% Coupon Volatility Series ( $\mathrm{t}$-statistics in parentheses)

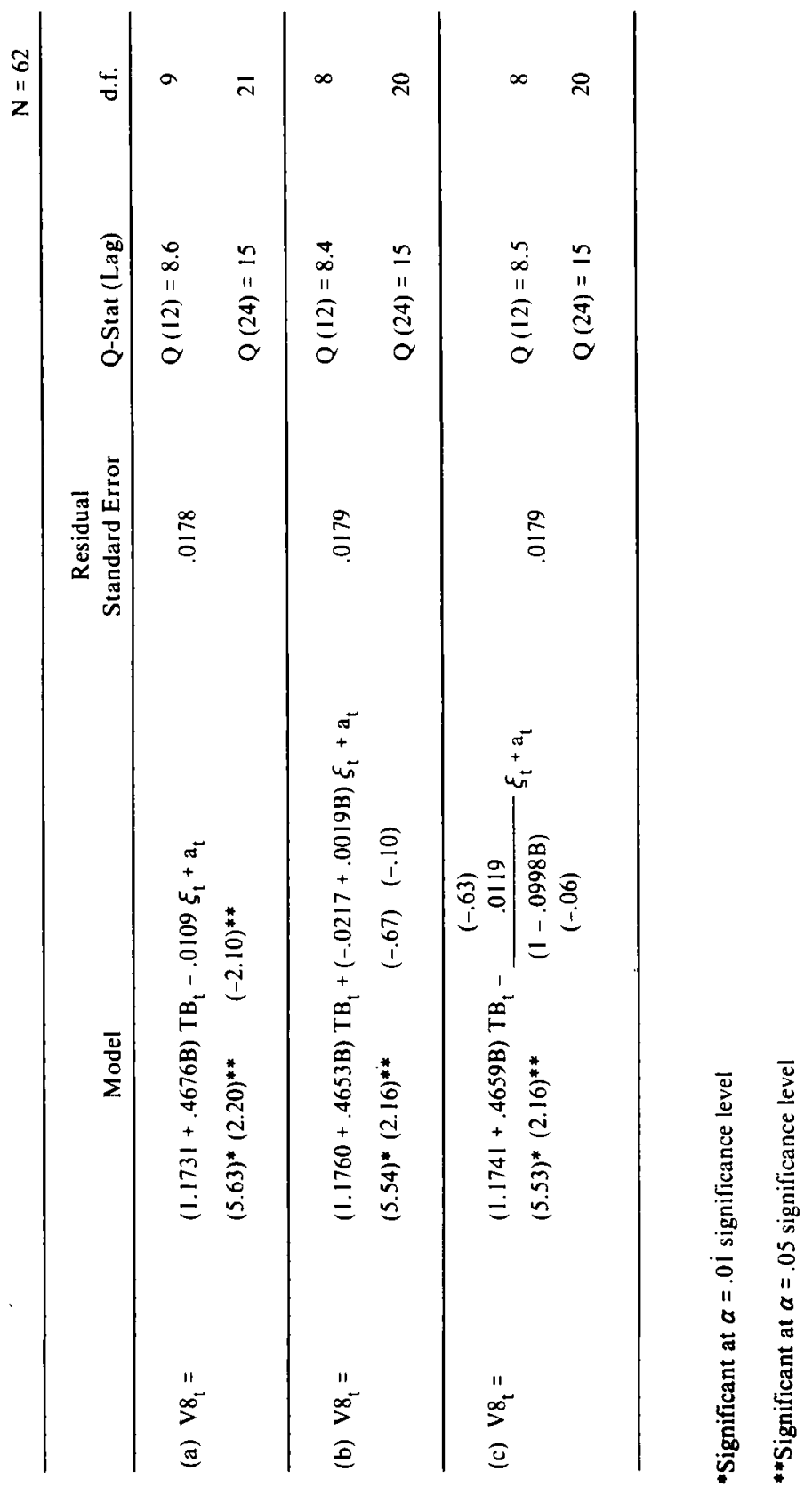


in GNMAs has served to stabilize cash market prices in accordance with current economic theory (Turnovsky 1983). Second, Figlewski [1981] finds that futures trading in GNMAs has had a destabilizing effect on the cash market in accordance with the speculator theory discussed in the first section of this study. Finally, in a study by Simpson and Ireland [1982], the cash market effects of the introduction of futures trading in GNMAs are shown to be neutral.

The empirical findings from this investigation which has attempted to resolve the problems of prior studies indicate that the introduction of futures trading has had a long-run stabilizing effect on the volatility of the cash market. The public policy implication of these findings are that since futures trading in GNMAs has not had a destabilizing effect on the cash market, ongoing mortgage credit policies and programs are not being undermined by GNMA futures trading. In addition, regulatory or administrative support for trading in mortgage futures may be justified on the grounds that furthering such trading will have a stabilizing effect on cash markets.

Research support from Georgia State University, College of Business Administration, is gratefully acknowledged. We have benefited from discussions with Benoit Deschamps and the assistance of Tae-Hyuk Kim.

\section{NOTES}

1. A similar conclusion is reached by Friedman, Harrison, and Salmon [1983] who observed futures and spot market trading in a controlled experimental auction market and conclude that futures markets promote a more efficient and less volatile spot market.

2. It might be argued that using prices in equation (1) is preferable to using yields. The advantage argued is primarily that problems regarding stationarity when working with "levels" are avoided. However, this argument applies equally to using prices. In any case, neither creates a problem in this study as the level of yields during our sample period was fairly stable. Some evidence of this can be seen in Table 1 which shows the generation of new issues. These new issues generally bore coupons of similar magnitude to those currently existing at their time of issue.

3. The GNMA futures contract calls for delivery of $\$ 100,000$ of GNMA $8 \%$ coupon at par or other coupons of equivalent principal balance calculated under the assumption of a 30-year certificate prepaid in the 12th year. However, even after the equivalent principal balance adjustment is made, one coupon will tend to be cheapest to deliver and the futures market will tend to price to this issue.

\section{REFERENCES}

[1] G. E. P. Box and G. M. Jenkins. Time Series Analysis: Forecasting and Control. Holden-Day, Inc., revised edition, 1976. 
[2] G. E. P. Box and G. C. Tiao. Intervention Analysis with Applications to Economic and Environmental Problems. Journal of the American Statistical Association 70: 70-79, March 1975.

[3] D. Cohen. Price Effects of Financial Futures Trading. Unpublished Ph.D. Dissertation, University of Florida. 1982.

[4] C. C. Cox. Futures Trading and Market Information. Journal of Political Economy 84: 1215-1237. December 1976.

[5] S. Figlewski. Futures Trading and Volatility in the GNMA Market. Journal of Finance 36: 445-456, May 1981 .

[6] D. Friedman, G. Harrison and J. Salmon. The Informational Role of Futures Markets: Some Experimental Evidence, Working paper, Columbia University, Center for the Study of Futures Markets, 1983.

[7] K. C. Froewiss. GNMA Futures: Stabilizing of Destabilizing? Federal Reserve Bank of San Francisco Economic Review 20-29, Spring 1978.

[8] R. M. Gardner. The Effects of the T-Bill Futures Market on the Cash T-Bill Market. Unpublished Manuscript, Chicago Mercantile Exchange, 1980.

[9] R. W. Gray. Onions Revisited. Journal of Farm Economics 45: 273-276, May 1963.

[10] A. C. Johnson. Effects of Futures Trading on Price Performance in the Cash Onion Market. USDA, ERS, Technical Bulletin, No. 1470, 1973.

[11] M. J. Powers. Does Futures Trading Reduce Price Fluctuations in the Cash Markets? American Economic Review 60: 460-464, June 1970.

[12] D. F. Seiders. Discussion-Futures Trading and Volatility in the GNMA Markets. Journal of Finance 36: 484-486, May 1981.

[13] W. G. Simpson and T. C. Ireland. The Effects of Futures Trading on the Price Volatility of GNMA Securities. Journal of Furures Markets, forthcoming.

[14] G. S. Taylor and R. M. Leuthold. The Influence of Futures Trading on Cash Cattle Price Variations. Food Research Institute Studies 13: 29-35, 1974.

[15] S. J. Turnovsky. The Determination of Spot and Futures Prices with Storable Commodities. Economerrica 51: 1363-1387, September 1983.

[16] H. Working. Price Effects of Futures Trading. Food Research Instinute Studies 1: 3-31, 1960.

[17] F. E. Zimring. Firearms and Federal Law: the Gun Control Act of 1968. Journal of Legal Studies 4: 133-198, January 1975. 